\title{
Intergenerational transmission of family meal patterns from adolescence to parenthood: longitudinal associations with parents' dietary intake, weight-related behaviours and psychosocial well-being
}

\author{
Jerica M Berge ${ }^{1, *}$, Jonathan Miller ${ }^{2}$, Allison Watts ${ }^{2}$, Nicole Larson ${ }^{2}$, Katie A Loth ${ }^{1}$ and \\ Dianne Neumark-Sztainer ${ }^{2}$ \\ 'Department of Family Medicine and Community Health, University of Minnesota Medical School, 717 Delaware \\ Street SE, Room 425, Minneapolis, MN 55414, USA: '2Division of Epidemiology and Community Health, University \\ of Minnesota, Minneapolis, MN, USA
}

Submitted 14 December 2016: Final revision received 15 July 2017: Accepted 18 July 2017: First published online 17 October 2017

\begin{abstract}
Objective: The present study examined longitudinal associations between four family meal patterns (i.e. never had regular family meals, started having regular family meals, stopped having regular family meals, maintained having regular family meals) and young adult parents' dietary intake, weight-related behaviours and psychosocial well-being. In addition, family meal patterns of parents were compared with those of non-parents.

Design: Analysis of data from the longitudinal Project EAT (Eating and Activity in Adolescents and Young Adults) study. Linear and logistic regressions were used to examine the associations between family meal patterns and parents' dietary intake, weight-related behaviours and psychosocial well-being.

Setting: School and in-home settings.

Subjects: At baseline (1998; EAT-I), adolescents ( $n$ 4746) from socio-economically and racially/ethnically diverse households completed a survey and anthropometric measurements at school. At follow-up (2015; EAT-IV), participants who were parents $(n$ 726) and who were non-parents with significant others ( $n$ 618) completed an online survey.

Results: Young adult parents who reported having regular family meals as an adolescent and as a parent ('maintainers'), or who started having regular family meals with their own families ('starters'), reported more healthful dietary, weightrelated and psychosocial outcomes compared with young adults who never reported having regular family meals ('nevers'; $P<0 \cdot 05$ ). In addition, parents were more likely to be family meal starters than non-parents.

Conclusions: Results suggest that mental and physical health benefits of having regular family meals may be realized as a parent whether the routine of regular family meals is carried forward from adolescence into parenthood, or if the routine is started in parenthood.
\end{abstract}

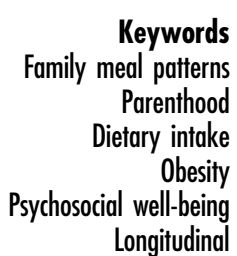

Prior cross-sectional and longitudinal studies have consistently found that having regular family meals is associated with multiple health benefits for adolescents and young adults, including healthful dietary intake ${ }^{(1-7)}$, lower levels of unhealthy weight-control behaviours ${ }^{(8,9)}$ and better psychosocial well-being ${ }^{(10-12)}$. Some studies have also shown associations between family meal frequency and lower risk for overweight in adolescence and young adulthood $^{(13-16)}$. Given the health benefits of regular family meals, it would be important to understand whether intergenerational transmission of family meal patterns/ routines occurs from one generation to the next.

Additionally, it would be important to know whether young adult parents who have engaged in different family meal frequency patterns (e.g. never had regular family meals as an adolescent or as a parent, started having regular family meals as a parent, stopped having regular family meals as a parent, maintained having regular family meals as an adolescent and as a parent) in adolescence and in parenthood have similar health benefits. 
For example, do young adults who discontinue regular family meals when they have their own family experience similar weight-related health outcomes as young adults who continue to have regular family meals with their own children? Or, do young adults who did not have regular family meals as adolescents but start having them once they have a family of their own experience the same weight-related health benefits of family meals in parenthood as young adults who always had regular family meals? Identifying how young adults' health outcomes are associated with different family meal frequency patterns from adolescence into parenthood will help inform whether the beneficial weight and weight-related health outcomes of having regular family meals can be realized whether the routine of regular family meals is carried forward from adolescence into parenthood or the routine of having regular family meals starts in parenthood. Furthermore, it is of interest to know whether having children increases the likelihood of young adults engaging in a certain family meal frequency pattern.

Overall, there is limited research examining the intergenerational transmission of family meal routines from adolescence to parenthood and few studies examining the association between family meal frequency patterns in adolescence and dietary, weight-related and psychosocial outcomes as a parent ${ }^{(15)}$. In addition, these associations have not been examined in a large community-based, racially/ethnically and socio-economically diverse sample. Thus, the main aim of the current study was to address the current gaps in the literature by examining four family meal frequency patterns from adolescence into parenthood, namely (i) never had regular family meals as an adolescent or as a parent, (ii) started having regular family meals as a parent, (iii) stopped having regular family meals as a parent and (iv) maintained having regular family meals from adolescence to parenthood, and their associations with young adults' dietary intake (fruit and vegetable intake, sugarsweetened beverage consumption, fast-food intake), weight and weight-related behaviours (weight status, unhealthy weight-control behaviours, binge eating), and psychosocial well-being (depression, self-esteem) as a parent.

Specific hypotheses to be tested in the current study include:

1. young adult parents who had regular family meals as adolescents and carry them forward (i.e. intergenerational transmission) with their own children will have better dietary intake, more healthy weight and weightrelated behaviours and higher psychosocial well-being compared with young adult parents who never have family meals, stop having regular family meals or do not start having regular family meals until they are parents; and

2. young adults who have children will be more likely to engage in regular family meals compared with young adults who are not parents.

\section{Theoretical framework}

The research question, hypothesis and analysis for the current study are guided by the Family Systems Theory (FST) ${ }^{(17-22)}$. According to FST, the family environment is the most proximal level of influence on child weight and weight-related behaviours. FST posits that behaviours learned in the family context in which a person is raised (e.g. having regular family meals, not having regular family meals) are passed on intergenerationally ${ }^{(23,24)}$. Furthermore, FST emphasizes the importance of creating healthful family patterns/routines (e.g. family meals) so that positive patterns are passed on to the next generation.

\section{Methods}

\section{Study design and population}

Data for the current analysis were drawn from the first (1998-1999) and fourth (2015-2016) waves of Project EAT (Eating and Activity in Teens and Young Adults), a longitudinal study designed to examine dietary intake, physical activity, weight-control behaviours weight status and factors associated with these outcomes among young adults. There were 1830 participants who completed both EAT-I (Wave 1) and EAT-IV (Wave 4) surveys. Compared with participants at baseline ( $n$ 4746), participants completing both Waves 1 and 4 of data collection were more likely to be female ( $57 \%$ compared with $45 \%$ at baseline, $\left.P\left(\chi^{2}\right)<0.0001\right)$, White race (68\% compared with $36 \%$ at baseline, $\left.P\left(\chi^{2}\right)<0 \cdot 0001\right)$ and have higher socio-economic status (19\% compared with $10 \%$ at baseline, $P$ $\left.\left(\chi^{2}\right)<0.0001\right)$.

The current analytic sample of parents includes 726 young adults who participated in Waves 1 and 4 of the Project EAT study, reported having one or more child(ren) (aged $\geq 1$ year) at Wave 4 , and lived with their own child(ren) at least $50 \%$ of the time at Wave 4 . To address study hypothesis 1 , only Waves 1 and 4 from the Project EAT study were used in analyses because the main aim of the study was to examine family meal patterns in adolescence (Wave 1) and in parenthood (Wave 4). To address hypothesis 2 (i.e. young adult parents will be more likely to engage in regular family meals than young adults who are not parents), we compared the 726 young adult parents with 618 non-parent participants who responded to both EAT-I and EAT-IV, reported having a significant other and had replied to a question about the frequency of eating family meals with their significant other.

\section{Survey development and fielding}

To allow for longitudinal comparisons and examination of secular trends, key items from earlier study waves of the study were retained on the Project EAT-IV survey. Decisions to retain or drop items were based on their relevance to the current study aims, their use in earlier analyses and the 
performance of represented constructs in the peer-reviewed literature. Additions to the survey were also made to reflect the study's life-course perspective and focus on learning about intergenerational influences on weight-related outcomes $^{(25)}$. Scale psychometric properties were examined in the full EAT-IV survey sample and estimates of item testretest reliability, reported below, were determined in a subgroup of 103 participants who completed the EAT-IV survey twice within a period of 1-4 weeks.

Invitations to complete the Project EAT-IV survey were mailed along with a two-dollar bill to all participants in the original sample who had responded to at least one previous follow-up survey. Most (83\%) of the sample was still living in Minnesota at EAT-IV, and all attempts to contact participants were by mail and online. Efforts to retain respondents who had moved from Minnesota were equal to efforts to retain respondents still in Minnesota. Survey invitation letters provided the web address and a unique password for completing the online version of the EAT-IV survey and an FFQ. To enhance participant response, a combination of US mail, email and text message reminders were sent to nonresponders. Individuals received up to six reminders; the final two mailed reminders included paper copies of the survey and FFQ, and all mailings provided the option to complete the survey by telephone. Reminder emails were additionally mailed to participants who did not complete the survey and FFQ after logging into the online version. Internet tracking services were employed to identify correct addresses when any mailing was returned due to an incorrect address. Surveys were completed by $66.1 \%$ of those who could be contacted at EAT-IV. Most respondents (95.4\%) completed the online survey. The University of Minnesota's Institutional Review Board Human Subjects Committee approved all protocols used in Project EAT at each wave.

\section{Measures}

Family meal frequency patterns

Family meal frequency was assessed at both EAT-I (19981999) and EAT-IV (2015-2016). In EAT-I participants were asked, 'During the past seven days, how many times did all, or most, of your family living in your house eat a meal together?' At EAT-IV participants were similarly asked, 'During the past seven days, how many times did all, or most, of the people living in your household eat a meal together?' (test-retest $r=0 \cdot 64$ ). At both time points the response options were: 'never', '1-2 times', '3-4 times', '5-6 times', ' 7 times' or 'more than 7 times'. A binary variable was created with participants reporting five or more family meals per week categorized as having regular family meals at EAT-I and at EAT-IV. Four family meal frequency patterns were then created including: nevers, stoppers, starters and maintainers. 'Nevers' reported having fewer than five family meals per week both at baseline and 15-year follow-up. 'Starters' reported not having five or more family meals per week at baseline but having five or more family meals at 15-year follow-up. 'Stoppers' reported having five or more family meals per week at baseline but not at 15-year follow-up. 'Maintainers' reported having five or more family meals per week both at baseline and 15-year follow-up. Frequencies for the original response options are shown in Table 1.

\section{Outcome measures}

Fruit and vegetable intake and sugar-sweetened beverage consumption. Intake of fruit and vegetables and consumption of sugar-sweetened beverages were measured at EAT-I and EAT-IV using a semi-quantitative FFQ, which comprehensively assessed overall usual past-year dietary intake $^{(26)}$. At EAT-IV, the FFQ was administered at the same time as the Project EAT-IV survey and included measures to allow for assessment of fruit, vegetable and sugar-sweetened beverage intakes ${ }^{(27)}$. A daily serving of fruit and vegetables was defined as the equivalent of onehalf cup and a serving of sugar-sweetened beverages was defined as the equivalent of one glass, bottle or can. Energy intakes were determined in 2016 by the Nutrition Questionnaire Service Center at the Harvard School of Public Health using a specially designed database, based primarily on the US Department of Agriculture's Nutrient Database for Standard Reference. Previous studies have examined and reported on the reliability and validity of intake estimates ${ }^{(28,29)}$. Responses to the FFQ were

Table 1 Reported family meal frequencies per week at EAT-I and EAT-IV; longitudinal data from Wave 1 (EAT-I; 1998-1999) and Wave 4 (EAT-IV; 2015-2016) of Project EAT (Eating and Activity in Teens and Young Adults)

\begin{tabular}{|c|c|c|c|c|c|c|c|c|c|c|c|c|}
\hline & \multicolumn{12}{|c|}{ EAT-IV } \\
\hline & \multicolumn{2}{|c|}{ Never } & \multicolumn{2}{|c|}{ 1-2 times } & \multicolumn{2}{|c|}{ 3-4 times } & \multicolumn{2}{|c|}{ 5-6 times } & \multicolumn{2}{|c|}{7 times } & \multicolumn{2}{|c|}{$>7$ times } \\
\hline & $n$ & $\%$ & $n$ & $\%$ & $n$ & $\%$ & $n$ & $\%$ & $n$ & $\%$ & $n$ & $\%$ \\
\hline EAT-I & \multicolumn{6}{|c|}{ Nevers } & \multicolumn{6}{|c|}{ Starters } \\
\hline Never & 3 & 0.4 & 12 & 1.7 & 27 & 3.7 & 24 & $3 \cdot 3$ & 9 & $1 \cdot 2$ & 37 & $5 \cdot 1$ \\
\hline 1-2 times & 1 & 0.1 & 5 & 0.7 & 30 & $4 \cdot 1$ & 25 & 3.4 & 21 & 2.9 & 67 & $9 \cdot 2$ \\
\hline 3-4 times & 1 & 0.1 & 22 & 3.0 & 32 & 4.4 & 31 & $4 \cdot 3$ & 14 & 1.9 & 71 & $9 \cdot 8$ \\
\hline & \multicolumn{6}{|c|}{ Stoppers } & \multicolumn{6}{|c|}{ Maintainers } \\
\hline 5-6 times & 0 & 0.0 & 12 & 1.7 & 20 & $2 \cdot 8$ & 29 & 4.0 & 17 & $2 \cdot 3$ & 72 & $9 \cdot 9$ \\
\hline 7 times & 0 & 0.0 & 7 & 1.0 & 6 & 0.8 & 7 & 1.0 & 10 & $1 \cdot 4$ & 21 & 2.9 \\
\hline$>7$ times & 0 & 0.0 & 11 & 1.5 & 12 & $1 \cdot 7$ & 16 & $2 \cdot 2$ & 9 & $1 \cdot 2$ & 45 & $6 \cdot 2$ \\
\hline
\end{tabular}


excluded if participants reported a biologically implausible level of total energy intake $(<2092 \mathrm{~kJ} / \mathrm{d}(<500 \mathrm{kcal} / \mathrm{d})$ or $>20920 \mathrm{~kJ} / \mathrm{d}(>5000 \mathrm{kcal} / \mathrm{d})$ ) or left twenty or more items blank (excluded $n$ 161). At EAT-I, a youth form of the FFQ was used to assess dietary intake and was administered at the same time as the Project EAT-I survey ${ }^{(1,30)}$.

Fast-food intake. Intake of fast foods from six categories of fast-food restaurants (i.e. burger-and-fries, fried chicken, Mexican, Asian, pizza, sandwich/sub) was assessed on the EAT-IV survey with the question, 'In the past month, how often did you eat something from the following types of restaurants (include take-out and delivery)?' Examples of quick-service and fast casual restaurant chains were provided for each type of fast-food restaurant. Response options were 'never/rarely', 'one to three times per month', 'one to two times per week', 'three to four times per week', 'five to six times per week' and 'one or more times per day.' This measure was adapted from a screener previously developed to assess restaurant use among adolescents ${ }^{(31)}$. The test-retest reliability of reported frequencies among young adults varied according to the type of food served at restaurants, ranging from $r=0.51$ (Asian food) to $r=0.71$ (sandwich/sub). At EAT-I, respondents were asked, 'In the past week, how often did you eat something from a fast food restaurant (like McDonald's, Burger King, Hardee's, etc.)?' There were six response options ranging from 'never' to 'more than 7 times'.

Weight status. Weight status at EAT-IV was calculated from self-reported height and weight. Self-reported height and weight have been shown to be highly correlated with objectively measured values in adults ${ }^{(32-35)}$. Heights and weights were converted to BMI and dichotomized as overweight $\quad\left(\mathrm{BMI} \geq 25.0 \mathrm{~kg} / \mathrm{m}^{2}\right)$ or non-overweight $\left(\mathrm{BMI}<25 \cdot 0 \mathrm{~kg} / \mathrm{m}^{2}\right)$. At EAT-I, weight status was calculated from measured height and weight.

Unhealthy weight-control behaviours. Unhealthy weightcontrol behaviours were assessed at EAT-I and EAT-IV with the following question, 'Have you done any of the following things in order to lose weight or keep from gaining weight during the past year?': (i) 'fasted'; (ii) 'ate very little food'; (iii) 'used a food substitute (powder or a special drink)'; (iv) 'skipped meals'; (v) 'smoked more cigarettes'; (vi) 'took diet pills'; (vii) 'made myself vomit'; (viii) 'used laxatives'; and (ix) 'used diuretics'. Participants responded to each behaviour with 'yes' or 'no' (test-retest $r=0 \cdot 82$ ). Unhealthy weight-control behaviours were coded as dichotomous variables (presence of any behaviour $v$. none), based on our previous research ${ }^{(36)}$.

Binge eating. Binge eating was assessed at EAT-I and EAT-IV using two items adapted from a scale by Yanovski ${ }^{(37)}$ : 'In the past year, have you ever eaten so much food in a short period of time that you would be embarrassed if others saw you (binge-eating)?' (percentage agreement $=90 \%$ at EAT-IV); and 'During the times when you ate this way, did you feel you couldn't stop eating or control what or how much you were eating?' (percentage agreement $=78 \%$ at EAT-IV). Participants responded 'yes' or 'no' to each item. Participants who answered 'yes' to both questions were coded as engaging in binge eating.

Depressive symptoms. Depressive symptoms were assessed at EAT-I and EAT-IV from a six-item standardized scale $^{(38)}$. An example item is, 'During the past 12 months, how often have you been bothered or troubled by feeling too tired to do things?' Responses ranged from 'not at all' to 'much'. Cronbach's $\alpha$ for these six items from EAT-IV in this sample was $0 \cdot 84$. The items were summed to get a depression score that ranges from 6 to 18, with higher scores indicating more depressive symptoms (test-retest $r=0.77$ ). In a comparable sample of high-school students, Kandel and Davies also found these items to have acceptable internal validity with a Cronbach's $\alpha$ of $0.79^{(38)}$.

Self-esteem. Self-esteem was assessed at EAT-I and EAT-IV from a six-item standardized scale ${ }^{(39)}$. An example item is, 'On the whole, I am satisfied with myself'. Responses were scored on a 4-point Likert scale ranging from 'strongly disagree' to 'strongly agree.' Cronbach's $\alpha$ for these six items from EAT-IV in this sample was $0 \cdot 85$. These items were summed to get a self-esteem score that ranges from 6 to 24, with higher scores indicating more self-esteem (test-retest $=0 \cdot 81$ ).

Sociodemographic characteristics. Age in years was calculated by subtracting the participant's self-reported birthdate from the date on which the survey was completed. Sex was self-reported as male or female at baseline. Race, reported at baseline, was dichotomized for the multivariate models to White and non-White because of small numbers in more specific categories of race. Socio-economic status (SES) was calculated primarily from the maximum educational attainment of the participants' parents with penalties for reporting being on public assistance or being unemployed ${ }^{(40)}$. The participant's relationship status at EAT-IV was self-reported and dichotomized for the multivariate models to married and unmarried. The participant's parents' relationship status at baseline was self-reported and dichotomized for the multivariate models to married and unmarried. Participants reported ages in years for each of the children living more than $50 \%$ of the time in their household; a mean age of the children living in the household was calculated from these reported ages.

\section{Statistical analyses}

Demographic descriptions of the family meal frequency patterns among those who were parents at EAT-IV were run, comparing age of the participant (at EAT-IV), mean age of children in the household (at EAT-IV), number of children in the household (at EAT-IV), participant's sex (at EAT-I), participant's race (at EAT-I), household SES (at EAT-I) and marital status of the participant's parents (at EAT-I) between the family meal frequency categories 
(nevers, starters, stoppers, maintainers; Table 2). Statistically significant differences $(P<0.05)$ in family meal frequency patterns were assessed with $\chi^{2}$ tests for categorical demographic variables and with ANOVA and $F$ tests for continuous demographic variables.

To address hypothesis 1 , a series of regression models were run to separately assess the association of family meal frequency pattern with each of the EAT-IV outcomes described above. All models were adjusted for age, sex, race (White $v$. non-White), parents' baseline SES, parents' baseline marital status (married $v$. unmarried), participant's current marital status (married $v$. unmarried), current mean age of children in the household, current number of children in the household, current education, the interaction between current education and baseline SES, and the baseline (EAT-I) level of the outcome variables. Linear regression was used for continuous outcomes (fruit and vegetable intake, sugar-sweetened beverage consumption, fast-food intake, unhealthy weight-control behaviours, depression, self-esteem). Continuous outcome variables were standardized to mean of 0 and SD of 1 . Effect sizes (regression coefficients) are reported for each category of family meal pattern for each outcome. The unhealthy weight-control behaviours variable was squareroot-transformed to account for substantial right skew in its distribution. Logistic regression was used for binary outcomes (overweight status, binge eating). Because the outcomes in the logistic regressions were fairly common (particularly overweight status), odds ratios do not approximate the relative risks. Therefore, the counterfactual method ${ }^{(41)}$ was used to calculate relative risks from the prediction equation estimated in the logistic regression. Standard errors for the relative risks were estimated using the delta method and method of variance recovery (MOVER) ${ }^{(42)}$ to allow estimation of confidence intervals for the relative risks (Table 3). To address hypothesis 2 , parents were compared with all non-parents ( $n$ 618) using $\chi^{2}$ tests to determine if family meal patterns differ by parent status. Parents were also compared with non-parents on demographic variables (Table 4).

All analyses were run in 2016 using the statistical software packages SAS version 9.4 (2011) and Stata version 13.1 (2013), and the epiR package in $\mathrm{R}$ version 3.2.2. Individual variables from the EAT-IV survey in this sample had relatively low missingness. Only the overweight status variables had greater than $5 \%$ of respondents missing ( 8.4 and $7.4 \%$ at EAT-I and EAT-IV, respectively). Because of non-response to the FFQ, there was greater missingness for the fruit and vegetable (missing $=26.7 \%$ ) and sugar-sweetened beverage (missing $=24.3 \%$ ) variables. However, under the missing at random assumption, missingness on the outcome will not bias the regression coefficients even if complete case analysis is used. For these reasons, all regressions were run as complete case analyses.

\section{Results}

Demographic correlates of changes in family meal frequency patterns among young adult parents

Among young adult parents, family meal frequency patterns over time tended to be similar across the following sociodemographic characteristics: sex, race/ethnicity, SES and number of children living in the household (Table 2). However, differences in meal patterns were observed for other demographic characteristics, including: mean age of child(ren) in household (i.e. starters and maintainers had younger children), age of the parent (i.e. stoppers and maintainers were younger parents) and marital status of the young adults' own parents (i.e. starters and maintainers were more likely to have had parents who were married).

\section{Associations between family meal frequency patterns and young adult parents' dietary intake, weight and weight-related behaviours, and psychosocial well-being}

\section{Dietary intake outcomes}

Results indicated that parents who maintained having regular family meals as adolescents and as parents, or who started the routine of having regular family meals as parents, consumed less fast food per week compared with those who reported never having regular family meals during adolescence or in parenthood (Table 3). For example, parents who maintained having regular family meal routines as an adolescent and as a parent reported $0 \cdot 13$ (95\% CI $-0 \cdot 23,-0 \cdot 03$ ) SD fewer fast-food meals per week than parents who never had regular family meals (Table 3). Parents who started having regular family meals when they became parents reported 0.16 (95\% CI -0.26, -0.06) SD fewer fast-food meals per week than parents who never had regular family meals (Table 3 ). There were no significant associations between family meal frequency patterns and young adult parents' fruit and vegetable intake or sugar-sweetened beverage consumption.

\section{Weight-related outcomes}

Results indicated that parents who maintained having regular family meals as adolescents and as parents, or who started the routine of having regular family meals as parents, engaged in significantly fewer unhealthy weightcontrol behaviours and had a lower risk of binge eating compared with those who reported never having regular family meals as an adolescent or as a parent (Table 3). There were no significant associations between family meal frequency patterns over time and young adult parents' weight status.

\section{Psychosocial outcomes}

Results indicated that parents who maintained having regular family meals as adolescents and as parents, or who started having regular family meals with their own 
Table 2 Demographic characteristics* ${ }^{*}$ of young adults by family meal frequency patterns at EAT-IV; data from Wave 4 (EAT-IV; 2015-2016) of Project EAT (Eating and Activity in Teens and Young Adults)

\begin{tabular}{|c|c|c|c|c|c|c|}
\hline & \multicolumn{2}{|c|}{ Total sample } & \multicolumn{4}{|c|}{ Family meal frequency trajectory† } \\
\hline & $n$ or Mean & $\%$ or SD & Nevers (\%) & Stoppers (\%) & Starters (\%) & Maintainers (\%) \\
\hline Overall, $n$ and $\%$ & 726 & $100 \cdot 00$ & $18 \cdot 3$ & $9 \cdot 4$ & $41 \cdot 2$ & $31 \cdot 1$ \\
\hline Age of young adult (years), mean and sD $\ddagger$ & 31.4 & 1.5 & 31.5 & $30 \cdot 7$ & $31 \cdot 3$ & $30 \cdot 7$ \\
\hline Age of children in household (years), mean and SD $\ddagger$ & 4.5 & $3 \cdot 2$ & $7 \cdot 4$ & $7 \cdot 0$ & $5 \cdot 7$ & $5 \cdot 8$ \\
\hline Number of children in household, mean and SD & $2 \cdot 1$ & $1 \cdot 1$ & $1 \cdot 8$ & 1.9 & $2 \cdot 0$ & $2 \cdot 0$ \\
\hline \multicolumn{7}{|l|}{ Sex of young adult, $n$ and $\%$} \\
\hline Male & 263 & 36 & $19 \cdot 2$ & $12 \cdot 7$ & $39 \cdot 2$ & 28.9 \\
\hline Female & 463 & 64 & $16 \cdot 1$ & $8 \cdot 6$ & $42 \cdot 6$ & $32 \cdot 7$ \\
\hline \multicolumn{7}{|l|}{ Race/ethnicity of young adult, $n$ and $\%$} \\
\hline White & 489 & 68 & $16 \cdot 3$ & $10 \cdot 8$ & $42 \cdot 5$ & $30 \cdot 3$ \\
\hline African American & 58 & 8 & $30 \cdot 3$ & $10 \cdot 4$ & $32 \cdot 1$ & $27 \cdot 2$ \\
\hline Hispanic & 28 & 4 & $16 \cdot 6$ & $5 \cdot 2$ & $35 \cdot 1$ & $43 \cdot 1$ \\
\hline Asian & 104 & 14 & $12 \cdot 6$ & $10 \cdot 9$ & $42 \cdot 8$ & 33.7 \\
\hline Mixed/other & 39 & 5 & $28 \cdot 1$ & $5 \cdot 4$ & 34.4 & $32 \cdot 1$ \\
\hline \multicolumn{7}{|l|}{ Socio-economic status of young adult, $n$ and $\%$} \\
\hline Low & 112 & 16 & $15 \cdot 6$ & $12 \cdot 7$ & $40 \cdot 8$ & $31 \cdot 0$ \\
\hline Mid/low & 120 & 17 & $23 \cdot 0$ & 12.4 & $36 \cdot 1$ & $28 \cdot 6$ \\
\hline Middle & 171 & 24 & $18 \cdot 8$ & 8.9 & $41 \cdot 7$ & $30 \cdot 6$ \\
\hline Mid/high & 213 & 30 & $16 \cdot 1$ & $5 \cdot 9$ & $48 \cdot 3$ & $29 \cdot 7$ \\
\hline High & 106 & 15 & $12 \cdot 7$ & $13 \cdot 7$ & $34 \cdot 3$ & $39 \cdot 4$ \\
\hline \multicolumn{7}{|l|}{ Young adult's parents' marital status, $n$ and \%‡ } \\
\hline Married & 492 & 69 & $16 \cdot 0$ & $11 \cdot 3$ & 38.0 & $34 \cdot 7$ \\
\hline Divorced & 139 & 19 & $24 \cdot 3$ & $7 \cdot 7$ & $47 \cdot 1$ & $20 \cdot 8$ \\
\hline Separated & 26 & 4 & $5 \cdot 5$ & $8 \cdot 6$ & $61 \cdot 8$ & $24 \cdot 1$ \\
\hline Never married & 43 & 6 & $10 \cdot 0$ & $7 \cdot 1$ & $63 \cdot 8$ & $19 \cdot 0$ \\
\hline One or both have died & 17 & 2 & 24.4 & $9 \cdot 7$ & 33.6 & $32 \cdot 3$ \\
\hline \multicolumn{7}{|l|}{ Young adult's relationship status, $n$ and \%‡ } \\
\hline Casually dating & 11 & 2 & $9 \cdot 4$ & $20 \cdot 9$ & $48 \cdot 4$ & $21 \cdot 3$ \\
\hline Committed dating relationship or engaged & 120 & 18 & $21 \cdot 2$ & $16 \cdot 4$ & $33 \cdot 3$ & $29 \cdot 1$ \\
\hline Married & 530 & 78 & $16 \cdot 4$ & $7 \cdot 2$ & 43.7 & $32 \cdot 6$ \\
\hline Domestic partner & 20 & 3 & $24 \cdot 1$ & 35.4 & $19 \cdot 8$ & $20 \cdot 6$ \\
\hline
\end{tabular}

*Values of polytomous variables may not sum to $100 \%$ due to rounding.

†Models comparing trajectories of family meals are mutually adjusted.

$\ddagger$ Variable is significantly related to family meal trajectory at $P<0.05$.

Table 3 Standardized associations* between family meal frequency pattern and young adults' dietary intake, weight and weight-related behaviours, and psychosocial well-being at EAT-IV; data from Wave 4 (EAT-IV; 2015-2016) of Project EAT (Eating and Activity in Teens and Young Adults)

\begin{tabular}{|c|c|c|c|c|c|c|c|c|}
\hline \multirow[b]{2}{*}{ Outcome } & \multicolumn{2}{|c|}{ Nevers } & \multicolumn{2}{|c|}{ Stoppers } & \multicolumn{2}{|c|}{ Starters } & \multicolumn{2}{|c|}{ Maintainers } \\
\hline & Estimate & $95 \% \mathrm{Cl}$ & Estimate & $95 \% \mathrm{Cl}$ & Estimate & $95 \% \mathrm{Cl}$ & Estimate & $95 \% \mathrm{Cl}$ \\
\hline \multicolumn{9}{|l|}{ Dietary intake } \\
\hline $\begin{array}{l}\text { Fruit and vegetable intake daily } \\
\text { servings } / 4184 \mathrm{~kJ}(1000 \mathrm{kcal}) \text { : ES }\end{array}$ & 0 & Ref. & 0.007 & $-0.09,0.10$ & 0.02 & $-0.10,0.13$ & 0.06 & $-0.06,0.18$ \\
\hline $\begin{array}{l}\text { Sugar-sweetened beverage intake } \\
\text { daily servings } / 4184 \mathrm{~kJ}(1000 \mathrm{kcal}) \text { : ES }\end{array}$ & 0 & Ref. & -0.004 & $-0.01,0.09$ & 0.006 & $-0 \cdot 11,0.12$ & 0.03 & $-0.10,0.14$ \\
\hline Fast-food intake† (weekly servings): ES & 0 & Ref. & -0.02 & $-0.11,0.07$ & $-0 \cdot 16 \ddagger$ & $-0.26,-0.06$ & $-0 \cdot 13 \ddagger$ & $-0.23,-0.03$ \\
\hline \multicolumn{9}{|l|}{ Weight-related outcomes } \\
\hline Overweight status: RR & 1 & Ref. & $1 \cdot 13$ & $0.77,1.57$ & 0.91 & $0.68,1 \cdot 20$ & 1.07 & $0.79,1.43$ \\
\hline $\begin{array}{l}\text { Unhealthy weight-control } \\
\text { behaviourst: ES }\end{array}$ & 0 & Ref. & -0.05 & $-0.13,0.03$ & $-0.14 \ddagger$ & $-0.25,-0.04$ & $-0 \cdot 11 \ddagger$ & $-0.22,-0.007$ \\
\hline Binge eatingt: RR & 1 & Ref. & 0.44 & $0.19,0.99$ & $0.42 \ddagger$ & $0.25,0.72$ & $0.52 \ddagger$ & $0.29,0.92$ \\
\hline \multicolumn{9}{|l|}{ Psychosocial well-being } \\
\hline Depressive symptomst: ES & 0 & Ref. & -0.02 & $-0.10,0.06$ & $-0.11 \ddagger$ & $-0.21,-0.003$ & $-0.13 \ddagger$ & $-0.24,-0.03$ \\
\hline Self-esteem†: ES & 0 & Ref. & 0.06 & $-0.02,0.14$ & $0.19 \ddagger$ & $0.08,0.29$ & $0.21 \ddagger$ & $0.11,0.32$ \\
\hline
\end{tabular}

ES, effect size; RR, relative risk; Ref., reference category; SES, socio-economic status.

${ }^{*}$ All models adjusted for parent age, sex, race (White $v$. non-White); mean age of children in the household; number of children in the household; current household SES; current marital status; baseline marital status; baseline SES; the interaction of current SES with baseline SES; and baseline measures of outcome variables.

†Statistically significant overall at $P<0.05$.

$\ddagger$ Significantly different from 'never' category at $P<0.05$. 
Table 4 Family meal patterns among parents and non-parent young adults at EAT-IV; data from Wave 4 (EAT-IV; 2015-2016) of Project EAT (Eating and Activity in Teens and Young Adults)

\begin{tabular}{|c|c|c|c|c|}
\hline & \multicolumn{2}{|c|}{$\begin{array}{l}\text { Parents } \\
(n \text { 726) }\end{array}$} & \multicolumn{2}{|c|}{$\begin{array}{c}\text { Non-parents } \\
(n \text { 618) }\end{array}$} \\
\hline & $n$ & $\%$ & $n$ & $\%$ \\
\hline \multicolumn{5}{|l|}{ Family meal pattern* } \\
\hline Never & 133 & $18 \cdot 3$ & 113 & $18 \cdot 3$ \\
\hline Starter & 299 & $41 \cdot 2$ & 208 & 33.7 \\
\hline Stopper & 68 & 9.4 & 98 & $15 \cdot 9$ \\
\hline Maintainer & 226 & $31 \cdot 1$ & 199 & $32 \cdot 2$ \\
\hline \multicolumn{5}{|l|}{ Sex $^{*}$} \\
\hline Female & 463 & 63.8 & 347 & $56 \cdot 2$ \\
\hline Male & 263 & $36 \cdot 2$ & 271 & 43.9 \\
\hline \multicolumn{5}{|l|}{ Race $^{*}$} \\
\hline White & 489 & $68 \cdot 1$ & 453 & 73.5 \\
\hline Non-White & 229 & 31.9 & 163 & $26 \cdot 5$ \\
\hline \multicolumn{5}{|l|}{ SES $^{*}$} \\
\hline High & 106 & $14 \cdot 7$ & 161 & $26 \cdot 4$ \\
\hline Low/medium & 616 & $85 \cdot 3$ & 448 & 73.6 \\
\hline \multicolumn{5}{|l|}{ Education* } \\
\hline Bachelor's degree or greater & 330 & $45 \cdot 6$ & 390 & 63.3 \\
\hline Less than bachelor's degree & 394 & 54.4 & 226 & 36.7 \\
\hline
\end{tabular}

*Parents and non-parents differ significantly at $P\left(x^{2}\right)<0.05$.

children, had fewer depressive symptoms and higher levels of self-esteem as compared with parents who never had regular family meals as adolescents (Table 3).

\section{Comparison of young adult parents v. non-parents on family meal frequency patterns}

Family meal patterns differed between young adult parents and other young adults who were not parents (Table 4). Parents were more likely to be family meal starters (41.2\%) than other young adults (33.7\%) and less likely to be family meal stoppers (9.4\%) than other young adults (15.9\%). Compared with participants who were not parents at EAT$\mathrm{IV}$, parents were more likely to be female (64\% of parents $v .56 \%$ of other young adults, $\left.P\left(\chi^{2}\right)=0.004\right)$, have medium or lower SES ( $85 \%$ of parents $v .74 \%$ of other young adults, $P\left(\chi^{2}\right)<0.0001$ ), be non-White $(32 \%$ of parents $v .27 \%$ of other young adults, $\left.P\left(\chi^{2}\right)=0.03\right)$ and were less likely to have attained at least a bachelor's degree ( $46 \%$ of parents $v .63 \%$ of other young adults, $\left.P\left(\chi^{2}\right)<0.0001\right)$.

\section{Discussion}

Results of the current study support each study hypothesis in part or in full. The first hypothesis was that young adult parents who had regular family meals as adolescents and carry them forward (i.e. intergenerational transmission) with their own children as parents will have better dietary intake, more healthy weight and weightrelated behaviours, and higher psychosocial well-being. This hypothesis was supported for the majority of the outcome measures. Among young adult parents, having regular family meals in both adolescence and parenthood
(15 years later), or starting to have regular family meals as a parent, was associated with more healthful dietary, weight-related and psychosocial outcomes in parents. These associations were found for many, but not all of the outcomes examined. For example, regular family meals were associated with less fast-food intake, fewer unhealthy weight-control behaviours, fewer depressive symptoms, less binge eating and higher self-esteem in parents. However, there were no significant associations between regular family meals and parent fruit and vegetable intake, sugar-sweetened beverage consumption or weight status. Study results reinforce prior cross-sectional and longitudinal findings that have shown regular family meals in adolescence are associated with healthier weight-related behaviours and emotional well-being in the short and long term $^{(1,10,14,15,43)}$. Results also extend previous longitudinal findings by showing that having regular family meals as a parent is associated with healthful dietary, weight-related and psychosocial outcomes, even if family meals were experienced less frequently in adolescence ${ }^{(1,10,14,15,43)}$.

The second study hypothesis, that young adults who have children will be more likely to engage in regular frequent family meals compared with young adults who are not parents, was supported. Young adults who were parents were more likely to start and less likely to stop having regular family meals compared with non-parents.

Results of the current study also support the tenets of the FST ${ }^{(17,18)}$ and other studies that have used FST to guide their research on family meals ${ }^{(19,22,44,45)}$. FST purports that patterns/routines (e.g. regular family meals) created in the family can be supportive and conducive to healthy behaviours/outcomes (e.g. healthy eating). Additionally, behaviours (i.e. having regular family meals) learned in adolescence can be transmitted intergenerationally. In the current study, intergenerational transmission of family meal patterns from adolescence into parenthood was associated with healthy dietary intake, weight-related behaviours and psychosocial outcomes in parenthood. Furthermore, results suggested that starting new patterns/ routines in parenthood regarding regular family meals was also associated with healthy dietary intake, weight-related behaviours and psychosocial outcomes in parents.

These findings have implications for health-care providers, public health interventionists and future research. For example, providers working with adolescents and their parents, or young adults and their families, may want to include recommendations that it's never too late to start having regular family meals in terms of realizing certain dietary, weight-related and psychosocial benefits as a parent. Such messages may be reassuring to parents who are worried about lacking experience with the practice of having family meals. Additionally, interventions and future research focused on increasing family meals may want to include educational messages for families and parents regarding the importance of starting regular family meals whenever possible and tips for parents who did not eat 
regular family meals as children, but who might want to start. Such information may help reduce the barriers or potential burdens identified in previous research regarding why family meals are sometimes hard for families to carry out $^{(46-48)}$. Furthermore, it may be important to conduct qualitative research with parents regarding their attitudes towards family meals, such as their reasons for (or against) carrying forward family meals or barriers to carrying forward family meals with their own families.

The current study has both strengths and limitations. One strength of the study is the longitudinal study design, allowing for examining practices used in the home during adolescence and in parenthood. Another strength is the ability to adjust for important demographic variables and baseline measures (during adolescence) of the outcome variables. There are also some study limitations relating to the self-report nature of survey research, challenges with retention over the 15-year follow-up period, measuring dietary intake with an FFQ tool and the timing of measures. First, social desirability bias may have occurred, given the self-report nature of survey research. Additionally, the oneitem measure of family meal frequency may not be as robust a measure as compared with using multiple items. A second limitation is that participants self-reported their height and weight. However, prior studies ${ }^{(32-35)}$ and results from a sub-study ( $n$ 125) conducted with Project EAT participants ${ }^{(49,50)}$ have shown high correlations between self-reported height and weight and objectively measured values in adults (i.e. $r=0.89-0.98$ ). Third, there is a potential for retention bias in the study due to differential loss to follow-up from EAT-I to EAT-IV. Participants who were followed to Wave 4 were significantly different on some sociodemographic characteristics (e.g. sex, SES) compared with the population sampled at Wave 1 . Therefore, findings from the present study may not be generalizable to other more diverse populations. A fourth limitation is that FFQ were used, which may not be as valid a measure as other tools such as multiple $24 \mathrm{~h}$ dietary recalls. Finally, while the longitudinal time frame of the study is a strength, it is unclear at what point in time the family meal frequency patterns actually changed for participants and thus conclusions cannot be drawn regarding specific time points at which starting or stopping regular family meals is more impactful than other time points.

\section{Conclusion}

Study results suggest that young adults who continued the routine of having regular family meals from adolescence into parenthood (i.e. maintainers) or who started the routine of having regular family meals with their own families (i.e. starters) had more healthful dietary, weightrelated and psychosocial outcomes compared with parents who never had regular family meals from adolescence to parenthood or those who stopped having regular family meals. Additionally, parents were more likely to be family meal starters than non-parents. Results of the current study may be useful for interventionists, health-care providers and future research to educate parents that it is never too late to start having regular family meals to realize certain benefits of healthy dietary, weightrelated and psychosocial outcomes as a parent.

\section{Acknowledgements}

Financial support: This research was supported by the National Heart, Lung, and Blood Institute (Principal Investigator D.N.-S., grant number R01HL116892). The content is solely the responsibility of the authors and does not necessarily represent the official views of the National Heart, Lung and Blood Institute, the National Institute of Child Health and Human Development or the National Institutes of Health. Conflict of interest: Authors have no conflicts of interest to report. Authorship: All co-authors made a substantial contribution to the paper as described below and agree to be accountable for all aspects of the work regarding the accuracy or integrity of any part of the work. J.M.B. conceptualized the paper, assisted with data analysis and interpretation, wrote all drafts of the paper, and gave final approval of the version to be published. J.M. conducted the data analysis, critically reviewed the paper, and gave final approval of the version to be published. A.W. assisted with data analysis and interpretation, critically reviewed the paper, and gave final approval of the version to be published. N.L. assisted with data acquisition, interpretation of the data, critically reviewed the paper, and gave final approval of the version to be published. K.A.L. assisted with conceptualization of the paper, critically reviewed the paper, and gave final approval of the version to be published. D.N.-S. is the Principal Investigator on the grant, she critically reviewed the paper, and gave final approval of the version to be published. Ethics of human subject participation: The University of Minnesota's Institutional Review Board Human Subjects Committee approved all protocols used in Project EAT at each wave.

\section{References}

1. Larson NI, Neumark-Sztainer D, Hannan PJ et al. (2007) Family meals during adolescence are associated with higher food quality and healthful meal patterns during young adulthood. J Am Diet Assoc 107, 1502-1510.

2. Gable S \& Lutz S (2000) Household, parent, and child contributions to childhood obesity. Fam Relat 49, 293-300.

3. Gillman MW, Rifas-Shiman SL, Frazier AL et al. (2000) Family dinner and diet quality among older children and adolescents. Arch Fam Med 9, 235-240.

4. Neumark-Sztainer D, Hannan PJ, Story M et al. (2003) Family meal patterns: associations with sociodemographic characteristics and improved dietary intake among adolescents. J Am Diet Assoc 103, 317-322. 
5. Berge JM, MacLehose RF, Loth KA et al. (2012) Family meals. Associations with weight and eating behaviors among mothers and fathers. Appetite 58, 1128-1135.

6. Larson N, Wang Q, Berge JM et al. (2016) Eating breakfast together as a family: mealtime experiences and associations with dietary intake among adolescents in rural Minnesota, USA. Public Health Nutr 19, 1565-1574.

7. Larson NI, Nelson MC, Neumark-Sztainer D et al. (2009) Making time for meals: meal structure and association with dietary intake in young adults. J Am Diet Assoc 109, 72-79.

8. Neumark-Sztainer D, Eisenberg ME, Fulkerson JA et al. (2008) Family meals and disordered eating in adolescents: longitudinal findings from Project EAT. Arch Pediatr Adolesc Med 162, 17-22.

9. Neumark-Sztainer D, Wall M, Story M et al. (2004) Are family meal patterns associated with disordered eating behaviors among adolescents? J Adolesc Health $\mathbf{3 5}$, 350-359.

10. Eisenberg ME, Olson RE, Neumark-Sztainer D et al. (2004) Correlations between family meals and psychosocial wellbeing among adolescents. Arch Pediatr Adolesc Med 158, 792-796.

11. Miller DP, Waldfogel J \& Han W-J (2012) Family meals and child academic and behavioral outcomes. Child Dev $\mathbf{8 3}$ 2104-2120

12. Utter J, Denny S, Robinson E et al. (2013) Family meals and the well-being of adolescents. J Paediatr Child Health 49 906-911.

13. Gable S, Chang Y \& Krull JL (2007) Television watching and frequency of family meals are predictive of overweight onset and persistence in a national sample of school-aged children. J Am Diet Assoc 107, 53-61.

14. Fulkerson JA, Neumark-Sztainer D, Hannan PJ et al. (2008) Family meal frequency and weight status among adolescents: cross-sectional and five-year longitudinal associations. Obesity (Silver Spring) 16, 2529-2534.

15. Berge JM, Wall M, Hsueh TF et al. (2015) The protective role of family meals for youth obesity: 10-year longitudinal associations. J Pediatr 166, 296-301.

16. Chan JC \& Sobal J (2011) Family meals and body weight. Analysis of multiple family members in family units. Appetite 57, 517-524.

17. Whitchurch GG \& Constantine LL (1993) Systems theory. In Sourcebook on Family Theories and Methods: A Contextual Approach, pp. 325-352 [PG Boss, WJ Doherty, R LaRossa et al., editors]. New York: Plenum Press.

18. Bertalanffy LV (1952) Theoretical models in biology and psychology. In Theoretical Models and Personality, pp. 24-38 [D Krech and GS Klein, editors]. Durham, NC: Duke University Press.

19. Fiese BH, Hammons A \& Grigsby-Toussaint D (2012) Family mealtimes: a contextual approach to understanding childhood obesity. Econ Hum Biol 10, 365-374.

20. Kitzman-Ulrich H, Wilson DK, St George SM et al. (2010) The integration of a family systems approach for understanding youth obesity, physical activity, and dietary programs. Clin Child Fam Psychol Rev 13, 231-253.

21. Wilson DK (2009) New perspectives on health disparities and obesity interventions in youth. J Pediatr Psychol 34, 231-244.

22. Berge JM (2009) A review of familial correlates of child and adolescent obesity: what has the 21st century taught us so far? Int I Adolesc Med Health 21, 457-483.

23. Berge JM, Meyer C, MacLehose RF et al. (2015) All in the family: correlations between parents' and adolescent siblings' weight and weight-related behaviors. Obesity (Silver Spring) 23, 833-839.

24. Pachuki M, Lovenheim M \& Harding M (2014) Within-family obesity associations: evaluation of parent, child and siblings relationships. Am J Prev Med 4, 623-630.
25. Fine A \& Kotelchuck M (2010) Rethinking MCH: The life course model as an organizing framework. Concept paper, version 1.1. https://www.hrsa.gov/ourstories/mchb75th/ images/rethinkingmch.pdf (accessed August 2017).

26. Harvard School of Public Health Nutrition Department (2008) HSPH Nutrition Department's File Download Site. https://regepi.bwh.harvard.edu/health/nutrition.html (accessed January 2008).

27. Harvard School of Public Health Nutrition Department (2011) HSPH Nutrition Department's File Download Site. https://regepi.bwh.harvard.edu/health/nutrition.html (accessed January 2011).

28. Feskanich D, Rimm E, Giovannucci E et al. (1993) Reproducibility and validity of food intake measurements from a semiquantitative food frequency questionnaire. J Am Diet Assoc 93, 790-796.

29. Rimm E, Giovannucci E, Stampfer M et al. (1992) Reproducibility and validity of an expanded self-administered semiquantitative food frequency questionnaire among male health professionals. Am J Epidemiol 135, 1114-1126.

30. Rockett HRH, Berkey CS, Field AE et al. (2001) Crosssectional measurement of nutrient intake among adolescents in 1996. Prev Med 33, 27-37.

31. Nelson M \& Lytle L (2009) Development and evaluation of a brief screener to estimate fast-food and beverage consumption among adolescents. J Am Diet Assoc 109, 730-734.

32. Stewart A (1982) The reliability and validity of self-reported weight and height. J Chronic Dis 35, 295-309.

33. Tehard B, van Liere MJ, Com Nougue C et al. (2002) Anthropometric measurements and body silhouette of women: validity and perception. J Am Diet Assoc 102, 1779-1784.

34. Kuczmarski MF, Kuczmarski RJ \& Najjar M (2001) Effects of age on validity of self-reported height, weight, and body mass index: findings from the Third National Health and Nutrition Examination Survey, 1988-1994. J Am Diet Assoc 101, 28-34.

35. Palta M, Prineas RJ, Berman R et al. (1982) Comparison of self-reported and measured height and weight. $\mathrm{Am} \mathrm{J}$ Epidemiol 115, 223-230.

36. Haines J, Neumark-Sztainer D, Eisenberg ME et al. (2006) Weight-teasing and disordered eating behaviors in adolescents: longitudinal findings from Project EAT (Eating Among Teens). Pediatrics 117, e209-e215.

37. Yanovski S (1993) Binge eating disorder: current knowledge and future directions. Obes Res 1, 306-324.

38. Kandel DB \& Davies M (1982) Epidemiology of depressive mood in adolescents: an empirical study. Arch Gen Psychiatr 39, 1205-1212.

39. Rosenberg M (1965) Society and the Adolescent Self Image. Princeton, NJ: Princeton University Press.

40. Neumark-Sztainer D, Story M, Hannan PJ et al. (2002) Overweight status and eating patterns among adolescents: where do youth stand in comparison to the Health People 2010 Objectives? Am J Public Health 92, 844-851.

41. Muller CJ \& MacLehose RF (2014) Estimating predicted probabilities from logistic regression: different methods correspond to different target populations. Int J Epidemiol 43, 962-970.

42. Zou GY (2009) Assessment of risks by predicting counterfactuals. Stat Med 28, 3761-3781.

43. Fulkerson JA, Story M, Mellin A et al. (2006) Family dinner meal frequency and adolescent development: relationships with developmental assets and high-risk behaviors. J Adolesc Health 39, 337-345.

44. Berge JM \& Saelens BE (2012) Familial influences on adolescents' eating and physical activity behaviors. Adolesc Med State Art Rev 23, 424-439. 
45. Fiese BH \& Schwartz M (2008) Reclaiming the Family Table: Mealtimes and Child Health and Wellbeing. Washington, DC: Society for Research in Child Development.

46. Fulkerson JA, Kubik MY, Rydell S et al. (2011) Focus groups with working parents of school-aged children: what's needed to improve family meals? J Nutr Educ Behav 43, 189-193.

47. Berge JM, Hoppmann C, Hanson C et al. (2013) Perspectives about family meals from single-headed and dual-headed households: a qualitative analysis. J Acad Nutr Diet 113, 1632-1639.
48. Berge JM, Hanson C \& Draxten M (2016) Perspectives about family meals from racially/ethnically and socioeconomically diverse households with and without an overweight/ obese child. Child Obes 12, 368-376.

49. Quick V, Wall M, Larson N et al. (2013) Personal, behavioral and socio-environmental predictors of overweight incidence in young adults: $10-\mathrm{yr}$ longitudinal findings. Int $J$ Behav Nutr Phys Act 10, 37.

50. Sirard JR, Hannan P, Cutler GJ et al. (2013) Evaluation of 2 self-report measures of physical activity with accelerometry in young adults. $J$ Phys Act Health 10, 85-96. 